\title{
OBSERVATIONS ON THE EFFECT OF CIGARETTE SMOKING ON THE FUSION FREQUENCY OF FLICKER
}

\author{
By P. S. LARSON, J. K. FINNEGAN, AND H. B. HAAG
}

(From The Department of Pharmacology, Medical College of Virginia, Richmond)

(Submitted for publication August 15, 1949; accepted, December 28, 1949)

The fusion frequency of flicker has been defined as the highest number of impulses the retino-cortical system can perceive in a unit of time. Results of measurement of the fusion frequency of flicker have been used as an index of the functional state of the retino-cortical system and by inference of the functional state of the central nervous system as a whole (1). Thus there is evidence that a decrease in fusion frequency of flicker parallels development of subjective fatigue (1), and that subjective relief of fatigue resulting from administration of such stimulant drugs as amphetamine (2), and desoxyephedrine ( 3 ), is paralleled by an increase in fusion frequency.

In the present study, we have measured the effect of cigarette smoking on the fusion frequency of flicker. This was motivated by two reasons. First, the initial phase of the action of nicotine is known to be one of stimulation and hence might well exert an effect on fusion frequency. Second, if the nicotine content of cigarette smoke is adequate to affect fusion frequency of flicker, then the smoking habits of the individual should be taken into account in fusion frequency studies on man.

\section{EXPERIMENTAL}

The apparatus used for measurement of fusion frequency of flicker was essentially similar to the one described by Simonson and Enzer (1). A single group of 20 habitual cigarette smokers (all inhalers) served as subjects for all experiments. In the smoking experiments, three control determinations were made just prior to smoking; additional controls were taken in the rare instance when one of the first three definitely deviated from the other two. Smoking was limited to a single cigarette of popular brand except in Experiment 4 (see below), and, after starting smoking, determinations were made at the intervals given in Table $\mathrm{I}$.

Experiment 1. Determination of the effect on fusion frequency of flicker of the first cigarette smoked in the morning, the experiment being conducted after breakfast between $8: 30$ and 10:30 a.m. The results are summarized in Table I, Part 1.

Experiment 2. Determination of the effect on fusion frequency of flicker of the first cigarette smoked in the afternoon, the subjects having abstained from smoking since the night before the experiment. The results are summarized in Table I, Part 2.

Experiment 3. Determination of the effect on fusion frequency of flicker of a cigarette smoked in the afternoon, the subjects having smoked as usual during the part of the day preceding this. The results are summarized in Table I, Part 3.

Experiment 4. Same as Experiment 1, except that the

TABLE I

Effect of smoking a cigarette on the fusion frequency of ficker

\begin{tabular}{|c|c|c|c|c|c|c|}
\hline \multirow{2}{*}{ Part no. } & \multirow{2}{*}{ Nature of experiment } & \multicolumn{5}{|c|}{ Fusion frequency.of "flicker.(mean \pm S.D.) } \\
\hline & & Control & $\begin{array}{l}\text { Three min. of } \\
\text { smoking }\end{array}$ & End of smoking & $\begin{array}{l}\text { Five min. after } \\
\text { smoking }\end{array}$ & $\begin{array}{c}15 \underset{\text { min. after }}{1 \text { smoking }} \\
\text { t. }\end{array}$ \\
\hline 1 & First cigarette of day (morning) & $45.7 \pm 2.7$ & $48.0 \pm 3.7$ & $47.8 \pm 3.8$ & $46.9 \pm 3.5$ & $46.6 \pm 3.3$ \\
\hline 2 & First cigarette of day (afternoon) & $46.4 \pm 3.6$ & $48.9 \pm 3.8$ & $48.6 \pm 3.5$ & $47.8 \pm 3.6$ & $46.9 \pm 3.4$ \\
\hline 3 & $\begin{array}{l}\text { Effect of a cigarette in afternoon } \\
\text { of a day of smoking as usual }\end{array}$ & $47.4 \pm 3.0$ & $48.1 \pm 3.3$ & $48.0 \pm 3.3$ & $47.6 \pm 3.4$ & $47.6 \pm 3.7$ \\
\hline 4 & $\begin{array}{l}\text { First cigarette of day contained } \\
\text { less than } 0.2 \% \text { nicotine }\end{array}$ & $46.7 \pm 3.3$ & $46.6 \pm 3.4$ & $46.3 \pm 3.3$ & $46.2 \pm 3.1$ & $46.0 \pm 3.3$ \\
\hline 5 & $\begin{array}{l}\text { Control exp. No smoking be- } \\
\text { fore or during exp. }\end{array}$ & $46.1 \pm 3.3$ & $46.0 \pm 3.6$ & $45.8 \pm 3.5$ & $45.6 \pm 3.3$ & $46.0 \pm 3.6$ \\
\hline
\end{tabular}


TABLE II

Comparison of morning with afternoon fusion frequency of flicker in smokers

\begin{tabular}{c|c|c|c}
\hline \hline \multirow{2}{*}{$\begin{array}{c}\text { Part } \\
\text { no. }\end{array}$} & Nature of experiment & \multicolumn{2}{|c}{$\begin{array}{c}\text { Fusion frequency of flicker } \\
\text { (mean } \pm \text { S.D.) }\end{array}$} \\
\cline { 3 - 4 } & \multicolumn{1}{|c|}{$\begin{array}{c}\text { Morning } \\
\text { Abstained from smoking } \\
\text { until after the morning } \\
\text { determination, then } \\
\text { smoked as usual }\end{array}$} & $46.7 \pm 3.3$ & $47.1 \pm 3.5$ \\
\hline 2 & $\begin{array}{c}\text { Abstained from smoon } \\
\text { until after the afternoon } \\
\text { determination }\end{array}$ & $46.7 \pm 3.7$ & $46.4 \pm 3.6$ \\
\hline
\end{tabular}

cigarette smoked contained less than $0.2 \%$ nicotine. The results are summarized in Table I, Part 4.

Experiment 5. A control experiment in which determinations of fusion frequency of flicker were made at comparable time intervals to the smoking experiments. The subjects abstained from smoking through the time of the day preceding and occupied by this test. For comparison with the smoking experiment a six or eight minute period was allotted as corresponding to the time taken to smoke a cigarette. The results are summarized in Table I, Part 5.

Experiment 6. Comparison of morning with afternoon fusion frequency of flicker in smokers abstaining from smoking until after the morning determinations, then smoking as usual through the rest of the day except for abstaining during the brief time needed for making the afternoon determinations. About five hours elapsed between the morning and afternoon determinations. The results are summarized in Table II, Part 1.

Experiment 7. Comparison of morning with afternoon fusion frequency of flicker in smokers abstaining from smoking until after the afternoon test. About five hours elapsed between the morning and afternoon determinations. The results are summarized in Table II, Part 2.

\section{DISCUSSION}

It is apparent from Table I, Parts 1 and 2, that in smokers the first cigarette smoked after a period of abstinence causes an immediate temporary increase in the fusion frequency of flicker. Evaluation of the differences between the control data and that obtained three minutes after beginning smoking indicates that the increases observed are statistically significant $(P=<.01)$. This effect is markedly reduced and is no longer significant when the time of abstinence is shortened to a period such as normally elapses between cigarettes (after the initial morning cigarette) in an average smoker (Table I, Part 3).
That the nicotine content of the cigarette tobacco is responsible for the effect described above is shown by its absence when the subjects smoked cigarettes containing less than $0.2 \%$ nicotine (Table I, Part 4). The average popular brand cigarette contains about $2 \%$ nicotine.

The results described above are further validated by the control experiment performed without smoking (Table I, Part 5) in which no tendency for a spontaneous elevation of the fusion frequency of flicker is evident.

Experiments 6 and 7 were performed to ascertain if with normal smoking throughout the day any depressing effect on fusion frequency of flicker develops. In Experiment 6, the morning fusion frequency before smoking was taken as a basis for comparison. A further basis for comparison was arrived at in Experiment 7, in which the subjects abstained from smoking until after the afternoon determinations. The results summarized in Table II, Parts 1 and 2, show that continued smoking through the day has no depressant effect on fusion frequency of flicker.

The mechanism of the elevating effect of nicotine on the fusion frequency of flicker is not apparent. It could represent a direct action on the nervous structures involved. On the other hand, the effect may be an indirect one. For example, the time-magnitude relations of this effect closely parallel those of the stimulant effect on blood pressure and heart rate that result from smoking a cigarette. Studies on circulatory insufficiency (4) and on circulatory stimulation (5) indicate that fusion frequency of flicker varies directly with the oxygen supply to the visual pathway. This leads to the possibility that the nicotine effect on fusion frequency results from improved circulation to the structures involved.

Whatever the mechanism, the results obtained indicate that the smoking habits of the individual should either be controlled when making fusion frequency of flicker measurements or at least known, so they can be weighed in making subsequent interpretations.

\section{CONCLUSIONS}

1. Following a period of abstinence from smoking, such as overnight, the first cigarette smoked causes an immediate increase in the fusion frequency of flicker. 
2. With continued smoking this effect becomes reduced.

3. The elevation in fusion frequency of flicker resulting from smoking a cigarette is due to the nicotine content of the cigarette tobacco.

4. The smoking habits of the individual should be taken into account in fusion frequency of flicker measurement.

\section{ACKNOWLEDGMENT}

We are indebted to Professor George W. Snedecor of Iowa State College for advice concerning the statistical treatment of our data.

\section{BIBLIOGRAPHY}

1. Simonson, E., and Enzer, N., Measurement of fusion frequency of flicker as a test for fatigue of the central nervous system; observations on laboratory technicians and office workers. J. Indust. Hyg. \& Toxicol., 1941, 23, 83.

2. Simonson, E., Enzer, N., and Blankstein, S. S., Effect of amphetamine (benzedrine) on fatigue of the central nervous system. War Med., 1941, 1, 690.

3. Simonson, E., and Enzer, N., Effect of pervitin (desoxyephedrine) on fatigue of the central nervous system. J. Indust. Hyg. \& Toxicol., 1942, 24, 205.

4. Enzer, N., Simonson, E., and Blankstein, S. S., Fatigue of patients with circulatory insufficiency, investigated by means of the fusion frequency of flicker. Ann. Int. Med., 1942, 16, 701.

5. Simonson, E., Enzer, N., and Benton, R. W., The influence of muscular work and fatigue on the state of the central nervous system. J. Lab. \& Clin. Med., 1943, 28, 1555. 